\title{
Urbanization and noncommunicable disease (NCD) risk factors: WHO STEPwise Iranian NCD risk factors surveillance in 2011
}

Zahra Khorrami, ${ }^{7}$ Koorosh Etemad, ${ }^{7}$ Shahin Yarahmadi, ${ }^{2}$ Soheila Khodakarim, ${ }^{7}$ Mohammadesmail Kameli, ${ }^{3}$ Alireza Mahdavi Hezaveh ${ }^{4}$ and Ebrahim Rahimi ${ }^{1,5}$

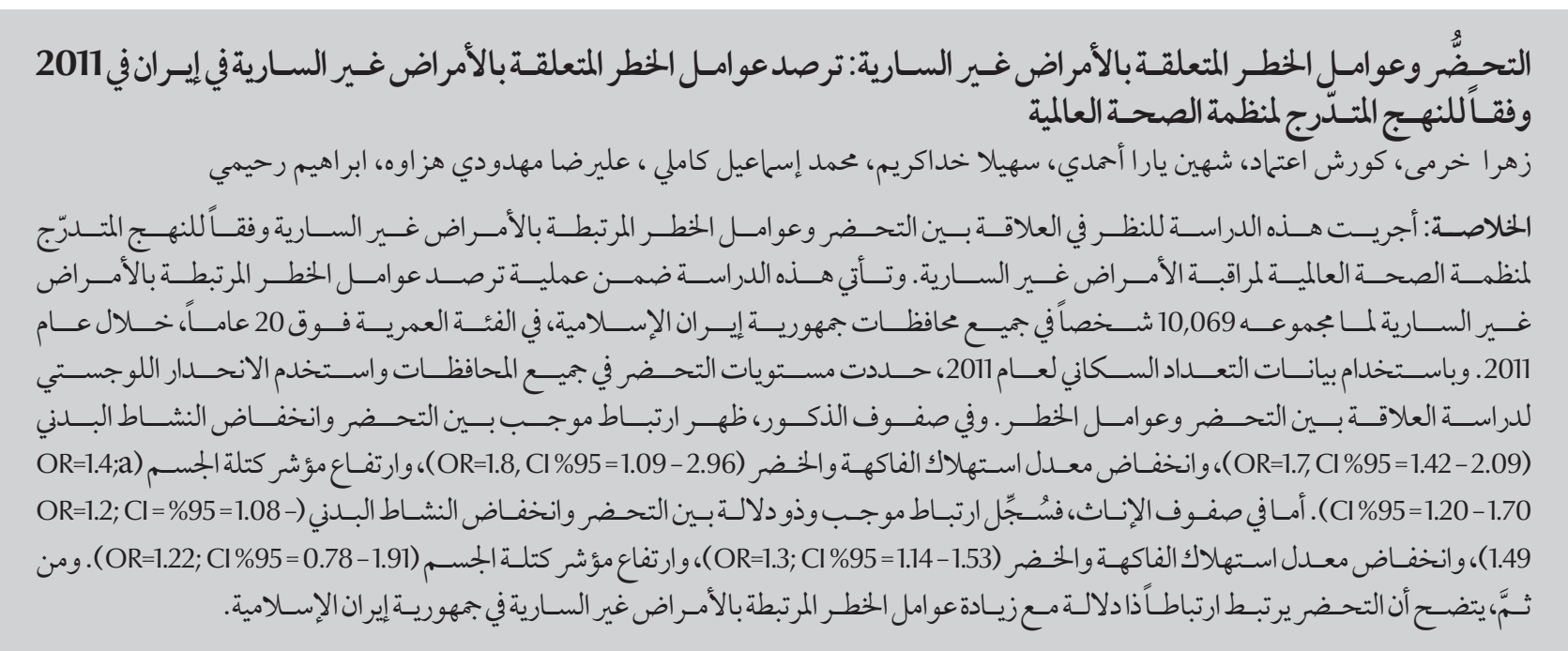

ABSTRACT This study was conducted to examine the relationship between urbanization and risk factors of noncommunicable diseases (NCDs) according to the World Health Organization stepwise approach to surveillance of NCDs. This study is part of a NCD risk factor surveillance of 10069 individuals in all provinces of the Islamic Republic of Iran, aged over 20 years, during 2011. By utilizing 2011 census data, urbanization levels were determined in all provinces and logistics regression was used to examine the relationship between urbanization and risk factors. Among males, urbanization had a positive correlation with low physical activity (OR=1.7; 95\% Cl: 1.42-2.09), low fruit and vegetable consumption ( $\mathrm{OR}=1.8 ; 95 \% \mathrm{Cl}$ : 1.09-2.96), and high $\mathrm{BMI}(\mathrm{OR}=1.4 ; 95 \% \mathrm{Cl}: 1.20-1.70)$. Among females there was a positive and significant correlation with low physical activity (OR=1.2; 95\% Cl: 1.08-1.49), low fruit and vegetable consumption ( $\mathrm{OR}=1.22 ; 95 \% \mathrm{Cl}$ : 0.78-1.91) and high $\mathrm{BMI}(\mathrm{OR}=1.3 ; 95 \% \mathrm{Cl}$ : 1.14-1.53). Thus, urbanization has a significant correlation with increases in NCD factors in the Islamic Republic of Iran.

Urbanisation et facteurs de risque de maladies non transmissibles (MNT) : approche STEPwise de I'OMS pour la surveillance des facteurs de risque de MNT en République islamique d'Iran en 2011

RÉSUMÉ La présente étude a été menée afin d'examiner la relation entre l'urbanisation et les facteurs de risque de MNT, selon le modèle de l'approche STEPwise de I'OMS pour la surveillance des maladies non transmissibles. L'étude s'inscrit dans la surveillance des facteurs de risque de MNT opérée sur 10069 personnes âgées de plus de 20 ans dans l'ensemble des provinces de la République islamique d'Iran en 2011. À I'aide de données du recensement de 2011, les niveaux d'urbanisation ont pu être déterminés pour toutes les provinces, et la régression logistique a été utilisée afin d'examiner la relation entre l'urbanisation et les facteurs de risque. Parmi les hommes, I'urbanisation avait une corrélation positive avec une faible activité physique (OR =1,7, IC à 95\%:1,42-2,09), une faible consommation de fruits et légumes $(O R=1,8$, IC à $95 \%: 1,09-2,96)$ et un indice de masse corporelle élevé ( $O R=1,4$, IC à $95 \%: 1,20-1,70)$. Parmi les femmes, il existait une corrélation positive et significative avec une faible activité physique $(\mathrm{OR}=1,2$, IC à $95 \%: 1,08-1,49)$, une faible consommation de fruits et légumes $(\mathrm{OR}=1,22$, IC à $95 \%$ : 0,78-1,91) et un indice de masse corporelle élevé ( $O R=1,3$, IC à $95 \%: 1,14-1,53)$. L'urbanisation a donc une corrélation significative avec l'augmentation des facteurs de MNT en République islamique d'Iran.

'Department of Epidemiology, School of Public Health, Shahid Beheshti University of Medical Sciences, Tehran, Islamic Republic of Iran (Correspondence to: Koorosh Etemad: etemadk@gmail.com). ${ }^{2}$ Endocrine and Metabolic Office; ${ }^{3}$ Office of Hospital Management and Clinical Service Excellence; ${ }^{4}$ Diabetes Control and Prevention Program, Center for Noncommunicable Diseases Control, Ministry of Health \& Medical Education, Tehran, Islamic Republic of Iran; ${ }^{5}$ Department of Epidemiology, Mamasani Higher Education Complex for Health, Shiraz University of Medical Sciences, Shiraz, Islamic Republic of Iran.

Received: 13/01/16; accepted: 16/11/16 


\section{Introduction}

It has been predicted that over $60 \%$ of the world population in low- and middle-income countries will be living in cities by 2030 (1). Certain lifestyle and environmental factors related to urbanization have a significant effect on health and noncommunicable diseases (NCDs). Urbanization is one of the main socioenvironmental factors which has a relationship with changing lifestyles as an important risk factor for NCDs (2). Previous research in low- and middle-income countries has indicated that NCD risk factors are more common in urban than in rural areas (3). In recent years, the increase in NCDs has been a common concern as a major cause of morbidity and mortality worldwide (4). It has been estimated that 33 million deaths in 2008 were due to NCDs, and this is predicted to reach 52 million by 2030 (5). Urbanization has an association with lifestyle and behavioural risk factors such as unhealthy diet and low physical activity $(6-8)$. Evidence from South-East Asia has indicated that urbanization has $a$ is associated with NCD risk factors such as low physical activity, unhealthy diet, overweight and high blood pressure $(9,10)$. In the past few decades, traditional communities in low- and middle-income countries have experienced rapid, unplanned urbanization, which changed lifestyles and resulted in unhealthy diets, a sedentary lifestyle and smoking (11). In the past, urban and rural environments were significantly different; however, the distinction is less clear now due to recent advances (12). Many definitions of urbanization only use the simple dichotomous variable of urban and rural, making it difficult to understand the specific changes within the urbanization process that have led to changes in the main risk factors for NCDs (13).

In recent years, there has been a rapid change in lifestyle and demographic and socioeconomic status in the Iranian community due to the escalation in urbanization and industrialization. The aim of this study was to investigate the association between urbanization and the risk factors for NCDs, which may lead to the identification of new, more effective interventions in the prevention of chronic diseases.

\section{Method}

\section{Study population and sampling}

We assessed the association between urbanization and NCD risk factors using the data from the 2011 survey of NCD risk factor surveillance (STEPS) conducted by the Ministry of Health and Medical Education in the 31 provinces of the Islamic Republic of Iran (14). The study population was 10069 people aged 20-70 years. A multistage random cluster sampling method with probability proportional to size sampling was used.

\section{Measuring urbanization}

Principal component analysis is a multivariate statistical method to reduce the number of variables (15). This method was used to create the urbanization variable; overall score is based on the score obtained using the xtile quint command in SPSS (percentiles of 33.3 and 66.7) in 3 categories low, medium and high.

There is no global standard indicator to measure urbanization because the factors associated with urbanization in one region of a country are different from those of others countries. From analysis of previous studies, the indices that had the greatest effect on urbanization were identified and included in this study $(13,16,17)$. Data on 24 variables measuring multiple aspects of urbanization (e.g. demographic and socioeconomic indices, human resources, communication, energy, the human development index for the province, and health and treatment indicators) were used to extract their underlying constructs. The principal components analysis-based index is a simple and robust measure whose values and groupings can only be moderately affected by changes in the urbanization landscapes. This multivariate statistical technique is used to reduce the number of variables in a data set into a smaller number of "dimensions" that are linear combinations of the original variables. Principal components analysis provides an objective way of aggregating the indicators so that variation in the data can be accounted for as concisely as possible. The urbanization index for all 31 provinces was calculated using this method and every province was classified into 3 urbanization levels. Variables such as average household size, population density, urbanization rate, average floor area of the dwelling unit per family member, economic participation rate, unemployment rate, employment in agriculture and industry, internet penetration, telephone and mobile penetration rate, percentage of villages with telephone communication, gas and electricity energy use per 1000 population, percentage of cities and rural areas with gas facilities, proportion of physicians per 1000 population, proportion of nurses per 1000 population, proportion of specialist physicians per 1000 population, and the human development index for each province were included in the analysis.

\section{Risk factors}

The data from the first and second stages of the 6th survey of risk factors for NCDs in 2011 in the Islamic Republic of Iran were used in this study (14). The NCD risk factors suggested by WHO such as demographic (residential location, age, gender, education, and job), nutrition (fruit and vegetable consumption), behavioural (smoking and physical activity), and anthropometric and blood pressure measurements were used in this survey. Anthropometric measurements include height, weight and body mass index (BMI) as an 
indicator of obesity. Blood pressure was measured 3 times at 3 minute intervals in a sitting position using an Omron electronic sphygmomanometer with an accuracy of $1 \mathrm{mmHg}$. Smoking was defined as daily cigarette and/or waterpipe consumption, low fruit and vegetable consumption as $<5$ units per day, and low physical activity as $<150 \mathrm{~min}$ of moderate intensity physical activity per week. The Global Physical Activity Questionnaire was used in this survey (18). High BMI was defined as $\geq 25 \mathrm{~kg} /$ $\mathrm{m}^{2}$, and high blood pressure as systolic blood pressure $>140 \mathrm{mmHg}$ and/or diastolic blood pressure $>90 \mathrm{mmHg}$ (16).

\section{Outcome variable}

We calculated the risk factor prevalence for each outcome within each level of urbanization. In addition, we investigated the relationship between risk factor and level of urbanization. Following WHO guidelines (19), we calculated the average consumption unit of fruits and vegetables a day, BMI, systolic and diastolic blood pressure, and age of starting smoking.

\section{Statistical methods}

The principal components analysis method was used to calculate the urbanization variable. Descriptive analysis was reported using descriptive statistics for every level of urbanization. The Kolmogorov-Smirnov test was utilized to assess the normality of variables. The 2-way Kruskal-Wallis test was used to assess the association between every continuous exposure variable and level of urbanization. Binary logistic regression analysis was used to explore the association between NCD risk factors and urbanization level. $P$-value $<0.05$ was considered significant, and SPSS, version 21, was used for all computations.

\section{Results}

\section{Urbanization index}

Urbanization scores ranged from -1.34 to 3.83 (Table 1). These were divided based on the scores obtained from xtile quint command (percentile of 33.3 and 66.7) into 3 categories: low, medium and high. Table 1 shows the distribution of provinces according to urbanization index. In the principal components analysis, variables such as internet penetration and provincial human development index achieved the greatest weight in comparison with other variables related to urbanization.

\section{Demographic characteristics}

The study population was aged $20-70$ [overall mean 43.00 (standard deviation 15.34)] years (Table 2). Individual education levels were higher with greater urbanization: $35.7 \%$ of those living in areas of low urbanization were illiterate while only $20.2 \%$ of those living in areas of high urbanization were illiterate.
Table 1 Urbanization index score of each province (each province to the new

index score of urbanization)

\begin{tabular}{lll}
\hline Province & Urbanization score & Urbanization level \\
Sistan and Baluchestan & -1.348 & Low \\
North Khorasan & -0.931 & \\
Ardebil & -0.889 & \\
Chaharmahal and Bakhtiari & -0.829 & \\
Kordestan & -0.794 & \\
Lorestan & -0.783 & \\
Ilam & -0.695 & \\
Western Azarbayjan & -0.690 \\
SouthKhorasan & -0.655 & \\
Hamedan & -0.521 & \\
Kohgiloyeh and Boyerahmad & -0.931 & \\
Kerman & -0.351 & \\
East Azarbayjan & -0.436 & \\
Golestan & -0.344 \\
Kermanshah & -0.342 & \\
Markazi & -0.306 & \\
Gilan & -0.004 & \\
Qazvin & 0.012 & \\
Fars & 0.013 & \\
Khuzestan & 0.127 & \\
Hormozgan & 0.149 & \\
Yazd & 0.156 & \\
Mazandaran & 0.157 & \\
Khorasan Razavi & 0.259 & \\
Zanjan & 0.434 & \\
Booshehr & 0.543 & \\
Semnan & 0.594 & \\
Esfahan & 0.757 & \\
Alborz & 1.000 & \\
\hline & 2.208 & \\
Tehran & & \\
\hline
\end{tabular}




\begin{tabular}{|c|c|c|c|c|}
\hline \multirow[t]{2}{*}{ Characteristic } & \multicolumn{3}{|c|}{ Urbanization level } & \multirow[t]{2}{*}{ Total } \\
\hline & Low & Medium & High & \\
\hline Participants, no. (\%) & $2025(20.1)$ & $4071(40.4)$ & 3973 (39.5) & 10069 \\
\hline Mean (SD) age (years) & $42.70(15.57)$ & $43.03(15.18)$ & $43.14(15.38)$ & $43.00(15.34)$ \\
\hline Age range (years) & $20-70$ & $20-70$ & $20-70$ & $20-70$ \\
\hline \multicolumn{5}{|l|}{ Sex, no. $(\%)^{*}$} \\
\hline Male & $786(38.8)$ & $1712(42.1)$ & 1637 (41.2) & $4135(41.1)$ \\
\hline Female & $1239(61.2)$ & 2359 (57.9) & 2335 (58.8) & $5933(58.9)$ \\
\hline \multicolumn{5}{|l|}{ Education status, no.(\%) } \\
\hline Illiterate & $722(35.7)$ & $1060(26)$ & $801(20.2)$ & $2583(25.7)$ \\
\hline Elementary & $387(19.1)$ & $884(21.7)$ & $923(23.2)$ & $2194(21.8)$ \\
\hline Junior high school & $270(13.3)$ & $663(16.3)$ & $583(14.7)$ & $1516(15.1)$ \\
\hline Diploma & $406(20.0)$ & $928(22.8)$ & $960(24.2)$ & $2294(22.8)$ \\
\hline Higher education & $237(11.7)$ & $535(13.1)$ & 701 (17.6) & $1473(14.6)$ \\
\hline \multicolumn{5}{|l|}{ Work status, no. (\%)* } \\
\hline Public sector employee & $92(4.5)$ & $257(6.3)$ & $271(6.8)$ & $620(6.2)$ \\
\hline Private sector employee & $93(4.6)$ & $265(6.5)$ & $296(7.5)$ & $654(6.5)$ \\
\hline Employed, self-employed & $412(20.3)$ & $819(20.1)$ & $688(17.3)$ & 1919 (19.1) \\
\hline Student, soldier & $129(6.4)$ & $237(5.8)$ & $292(7.3)$ & $658(6.5)$ \\
\hline $\begin{array}{l}\text { Housewife, retired, unpaid work, } \\
\text { unemployed, disabled }\end{array}$ & $1275(63.0)$ & $2490(61.2)$ & $2415(60.8)$ & $6180(61.4)$ \\
\hline
\end{tabular}

Values are expressed as mean and standard deviation $(S D)$ for normally distributed data and \% for non-normally distribute data. * Significance defined as $P<0.05$.

There was also a significant difference in terms of employment among different urbanization levels $(P<0.05)$ (Table 2).

\section{Urbanization and noncommunicable disease risk factors}

\section{Tobacco}

The prevalence of smoking among men was similar in all 3 urbanization levels (Table 3). In univariate logistic regression analysis, there was no significant association between smoking and urbanization among men $(\mathrm{OR}=$ 1.02, 95\% CI: $0.84-1.24$ for medium and $\mathrm{OR}=0.90,95 \% \mathrm{CI}: 0.74-1.10$ for high versus low levels of urbanization) or women $(\mathrm{OR}=0.70,95 \% \mathrm{CI}$ : $0.50-0.99$ for medium and $\mathrm{OR}=0.85$,
95\% CI: $0.61-1.19$ for high versus low levels of urbanization) (Table 4). In multiple logistic regression analysis after adjustment for age, there was still no significant association between smoking and urbanization in men and women. Among those living in higher levels of urbanization, the average age of starting smoking was lower in both sexes, and

Mean age of starting smoking (year)
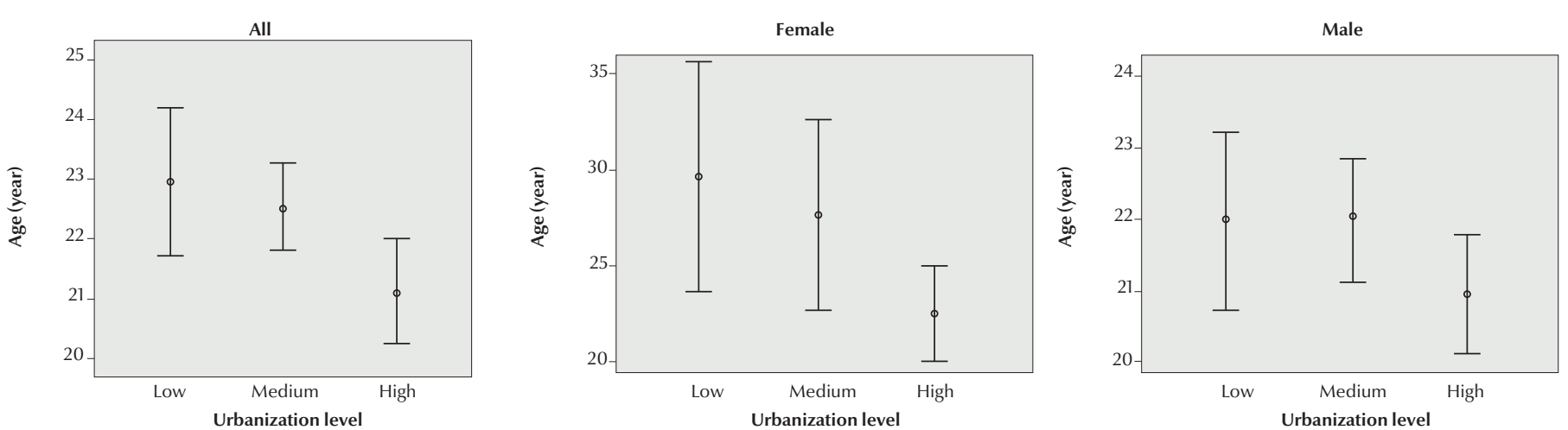

Figure 1A Mean of noncommunicable disease risk factor variables in urbanicity groups, Islamic Republic of Iran, 2011 


\begin{tabular}{|c|c|c|c|c|c|c|c|c|c|c|}
\hline \multirow[t]{2}{*}{ Risk factor } & \multirow{2}{*}{$\begin{array}{c}\text { Urbanization } \\
\text { level }\end{array}$} & \multicolumn{3}{|c|}{ Males } & \multicolumn{3}{|c|}{ Females } & \multicolumn{3}{|c|}{ All } \\
\hline & & No. & $\%$ & $95 \% \mathrm{Cl}$ & No. & $\%$ & $95 \% \mathrm{Cl}$ & No. & $\%$ & $95 \% \mathrm{Cl}$ \\
\hline \multirow{3}{*}{$\begin{array}{l}\text { Daily tobacco } \\
\text { use }\end{array}$} & Low & 208 & 26.5 & 23.42-29.58 & 59 & 4.8 & $3.63-5.97$ & 267 & 13.2 & $11.73-14.67$ \\
\hline & Medium & 471 & 27.5 & 25.39-29.61 & 80 & 3.4 & $2.67-4.13$ & 551 & 13.5 & $12.46-14.54$ \\
\hline & High & 414 & 25.3 & $23.20-27.40$ & 96 & 4.1 & $3.30-4.90$ & 510 & 12.8 & 11.77-13.83 \\
\hline \multirow{3}{*}{$\begin{array}{l}\text { Low physical } \\
\text { activitya* }\end{array}$} & Low & 252 & 32.1 & 30.44-33.76 & 536 & 43.3 & $40.56-46.04$ & 788 & 38.9 & 36.78-41.02 \\
\hline & Medium & 666 & 38.9 & $36.61-41.19$ & 999 & 42.3 & $40.32-44.28$ & 1665 & 40.9 & $39.40-42.41$ \\
\hline & High & 690 & 42.2 & 39.81-44.59 & 1103 & 47.2 & $45.19-49.21$ & 1793 & 45.1 & $43.56-46.64$ \\
\hline \multirow{3}{*}{$\begin{array}{l}\text { Low fruit \& } \\
\text { vegetable } \\
\text { intakeb* }\end{array}$} & Low & 609 & 77.5 & 74.59-80.41 & 1012 & 81.7 & 79.56-83.14 & 1621 & 80.0 & $78.26-81.74$ \\
\hline & Medium & 1455 & 85.0 & 83.31-86.96 & 2042 & 86.6 & 85.23-87.97 & 3497 & 85.9 & $84.84-86.96$ \\
\hline & High & 1370 & 83.7 & 81.92-85.57 & 1959 & 83.9 & 82.41-85.39 & 3330 & 83.8 & $82.66-84.94$ \\
\hline \multirow[t]{3}{*}{ High BMlc* } & Low & 356 & 45.3 & 41.83-48.77 & 711 & 57.4 & 54.65-60.15 & 1067 & 52.7 & $50.53-54.87$ \\
\hline & Medium & 866 & 50.6 & $48.24-52.96$ & 1461 & 61.9 & 59.95-63.85 & 2327 & 57.2 & 55.69-58.71 \\
\hline & High & 910 & 55.6 & $53.20-58.00$ & 1488 & 63.7 & $61.75-65.65$ & 2399 & 60.4 & 58.88-61.92 \\
\hline \multirow{3}{*}{$\begin{array}{l}\text { High blood } \\
\text { Pressured* }\end{array}$} & Low & 125 & 15.9 & 13.35-18.45 & 210 & 16.9 & 14.82-18.98 & 335 & 16.5 & 14.89-18.11 \\
\hline & Medium & 335 & 19.6 & $17.73-21.47$ & 489 & 20.7 & 19.07-22.33 & 824 & 20.2 & $18.97-21.43$ \\
\hline & High & 237 & 14.5 & $12.81-16.20$ & 310 & 13.3 & $11.93-14.67$ & 547 & 13.8 & $12.73-14.87$ \\
\hline
\end{tabular}

Low fruit \& vegetable intake significant only for men.

$\mathrm{Cl}=$ confidence interval.

$B M I=$ body mass index

${ }^{a_{<}} 150$ min of moderate or intense physical activity per week.

$b_{<}<5$ servings of fruit and vegetables per day.

${ }^{c} B M I \geq 25 \mathrm{~kg} / \mathrm{m}$.

${ }^{d}$ Systolic blood pressure $\geq 140 \mathrm{mmHg}$ and/or diastolic blood pressure $\geq 90 \mathrm{mmHg}$.

*Kruskall-Wallace test, significant at $P<0.05$.

smoking was more prevalent among the prevalence of low physical activity women (Figure 1A).

\section{Low physical activity}

Urbanization had an inverse association with physical activity in both sexes: increased significantly with increased urbanization (Table 3). In multiple logistic regression analysis after adjustment for age, there was a statistically significant association between low physical activity and urbanization in men $(\mathrm{OR}=1.58,95 \% \mathrm{CI}: 1.30-1.91$ for medium and $\mathrm{OR}=1.72,95 \% \mathrm{CI}$ : 1.42-2.09 for high versus low levels of urbanization) and women ( $\mathrm{OR}=$ 1.36, $95 \%$ CI: $1.15-1.60$ for medium

Mean fruits and vegetables intake per day (servings)
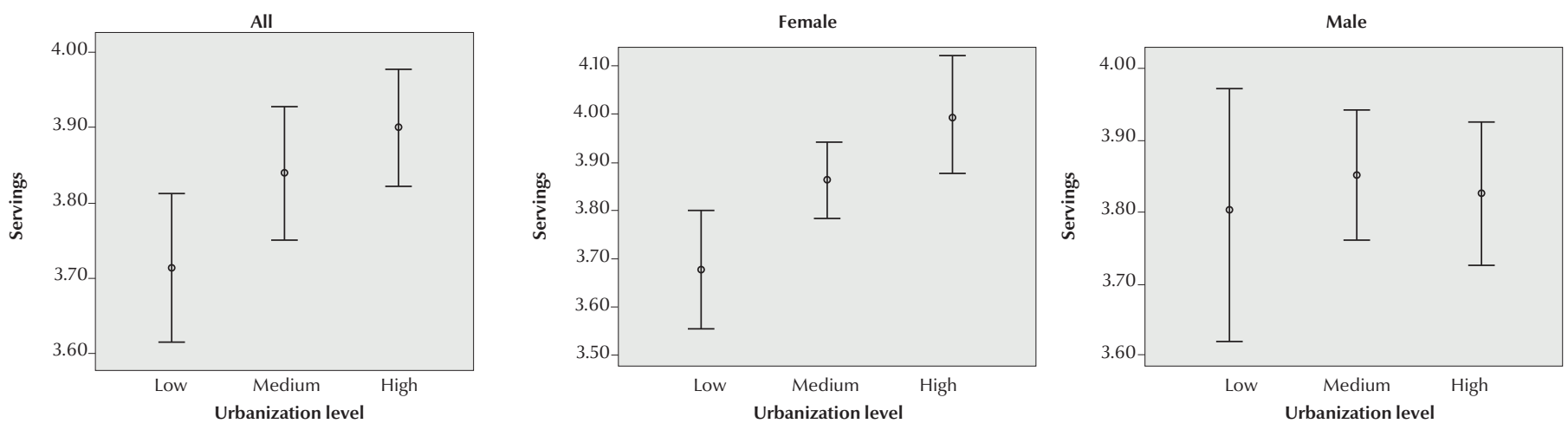

Figure 1B 


\section{Mean BMI $(\mathrm{kg} / \mathrm{m} 2)$}

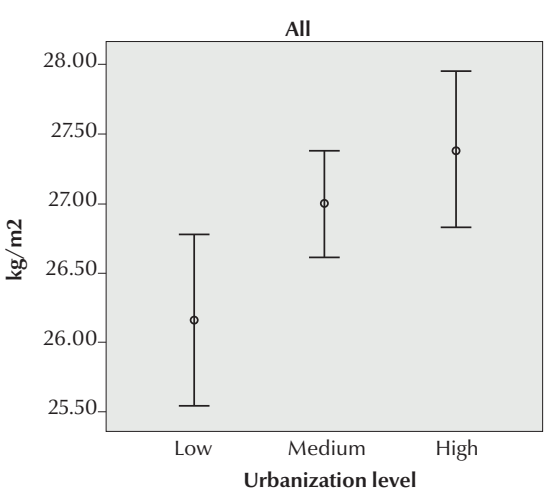

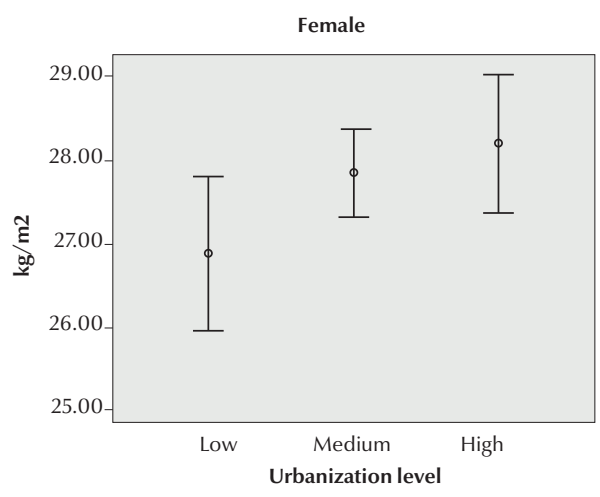

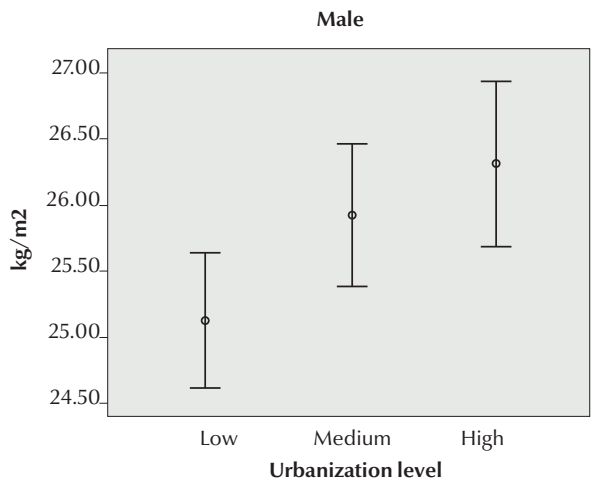

Figure 1C

and $\mathrm{OR}=1.26,95 \% \mathrm{CI}: 1.08-1.49$ for high versus low levels of urbanization) (Table 4).

\section{Low fruit and vegetable consumption}

In both sexes, the prevalence of low fruit and vegetable consumption increased with increased urbanization, but this was significant only for men (Table 3). With increasing urbanization, the odds of low consumption of fruits and vegetables increased. Men who were living in provinces with a medium level of urbanization were 2.10 times more likely (crude OR $=2.10$, 95\%CI: 1.26 3.48) and those living in provinces with a high level of urbanization 1.81 times more likely (crude OR $=1.81,95 \% \mathrm{CI}$ : 1.10-2.98) to have low fruit and vegetable consumption in comparison with those living in areas with a low level of urbanization. This association did not change after adjustment for age in multiple logistic regression. This positive relationship was also seen in women, but it was not statistically significant (Table 4). We also found a small difference between the mean servings of fruits and vegetables consumed per day for both sexes at different levels of urbanization $(P<0.05)$ (Table 5 and Figure 1B).

\section{High body mass index}

The prevalence of higher BMI levels (obese and overweight) in both sexes was positively related to increased urbanization (Table 3). The odds of men having high BMI levels in medium and high levels of urbanization were 1.18 (crude OR = 1.18, 95\% CI: 0.99-1.40) and 1.44 (crude OR $=1.44,95 \% \mathrm{CI}$ : $1.21-1.71)$ in comparison with lower levels of urbanization (Table 4). There was also a significant association between high BMI and urbanization in women $(\mathrm{OR}=1.21,95 \% \mathrm{CI}: 1.05-1.29$ for medium and $\mathrm{OR}=1.30,95 \% \mathrm{CI}$ : 1.13-1.50 for high versus low levels of urbanization). These associations did not change after adjustment for age in multiple logistic regressions. Moreover, a statistically significant association was observed between urbanization and mean BMI in both sexes as a continuous variable $(P<0.001)$ (Table 5 and Figure 1C).

\section{High blood pressure}

A higher prevalence of high blood pressure was observed in areas with medium

\section{Mean systolic blood pressure $(\mathrm{mmHg})$}

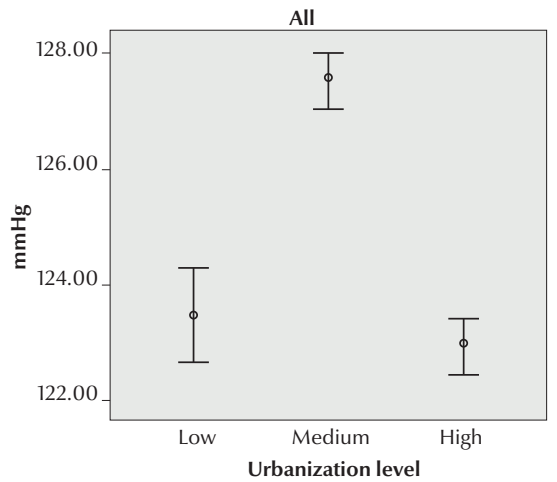

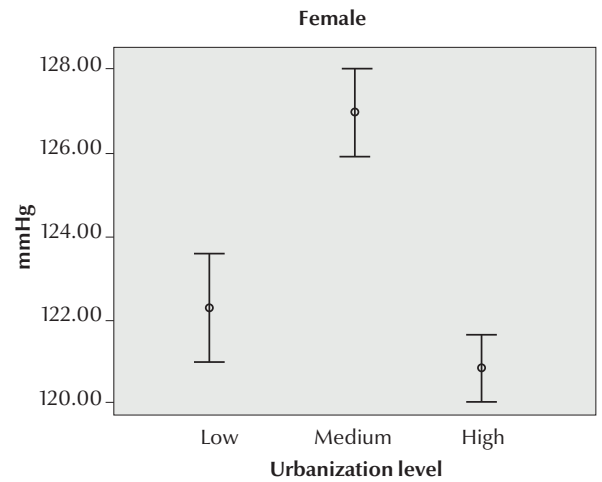

Figure 1D 
Mean diastolic blood pressure $(\mathrm{mmHg})$
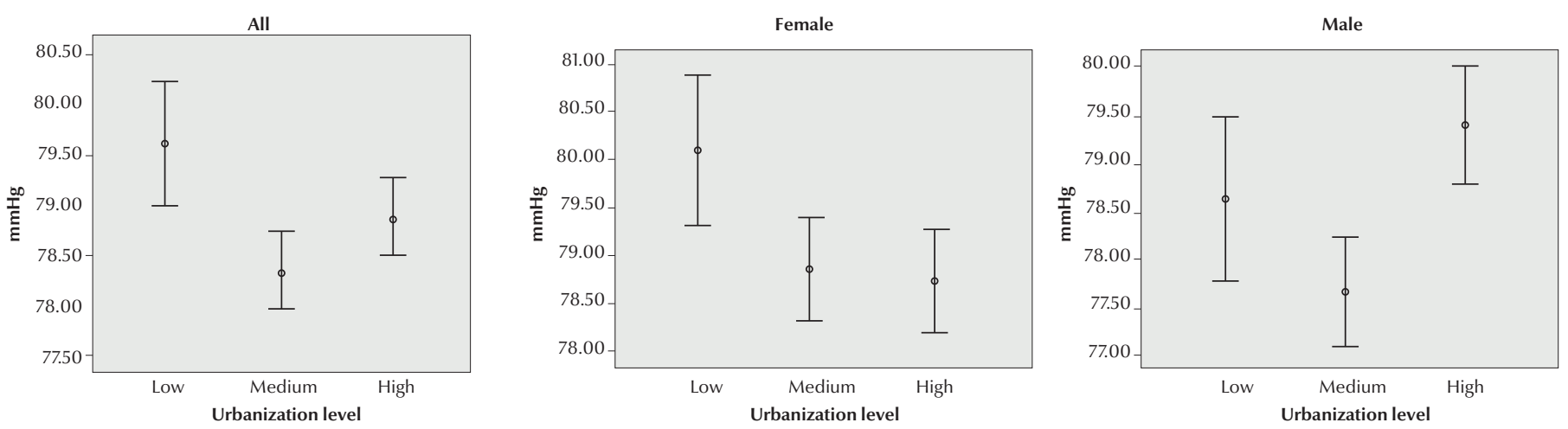

Figure 1E

levels compared with areas with low levels of urbanization for both sexes (Table 3). The same observation was not seen for areas with high levels of urbanization. In univariate logistic regression analysis, there was a significant association between high blood pressure and urbanization in men $(\mathrm{OR}=$ $1.25,95 \%$ CI: $1.00-1.57$ ) for medium versus low levels of urbanization and women for medium ( $\mathrm{OR}=1.29,95 \%$ CI: 1.08-1.54) and for high ( $\mathrm{OR}=0.78$, 95\% CI: 0.64-0.94) versus low levels of urbanization. This association did not change after adjustment for age in multiple logistic regression (Table 4). In addition, using the Kruskal-Wallis test, mean systolic and diastolic blood pressure had a significant association with level of urbanization in both sexes $(P<0.001)$ (Table 5 and Figures 1D and $1 \mathrm{E})$.

\section{Discussion}

Our findings support the hypothesis that there is a relationship between urbanization and NCD risk factors: urbanization had a positive association with low physical activity, low intake of fruit and vegetables, BMI and hypertension in both sexes. In 2009, a study conducted in the Islamic Republic of Iran reported a relationship between urbanization and risk factors of NCD, such that prevalence of NCD risk factors increased with increasing urbanization, consistent with our findings (20). A study conducted in India indicated that there was a relationship between smoking and urbanization in men (21). In our study, however, no such significant association was observed. Nevertheless, the results showed that with increasing urbanization the age of starting smoking decreased; this relationship was more evident in women, suggesting that preventive measures should be taken along with education about the dangers and side-effects of smoking in high-risk groups. In Qingdao, China, researchers found that urbanization was related to a number of risk factors such as low physical activity, unhealthy diet and obesity (21), consistent with the results of this study. Liu et al. found that urban development significantly reduced daily physical activity and increased the consumption of high calorie foods (fast food) (22). It has consequently led to a rapid increase in obesity and overweight due to changes in diet and lifestyle which significantly affect health $(12,23,24)$. A study from India showed no significant relationship between the prevalence of low fruit and vegetable consumption and different levels of urbanization in either sex (16). Unlike the Indian study, we found significant differences in the prevalence of low fruit and vegetable consumption among different levels of urbanization before and after ageadjusted analyses. In a study conducted in Greenland, no relationship was found between unhealthy dietary patterns and urbanization or socioeconomic status (25). In a study in 100 countries, Ezzati et al. found that BMI increased with increasing urbanization (26). Our findings indicate that with increasing urbanization, average BMI, high blood pressure, and low physical activity increased, consistent with previous studies (27-29). We found the prevalence of physical activity was higher in areas with low urbanization than in areas with high urbanization, consistent with the results of other studies (30,31). In a study in Sri Lanka, men and women in areas with high urbanization had respectively 3 and 2 times lower physical activity than those living in other urban areas, which was significant after age adjustment (32). Monda et al. also found that low physical activity increased with increasing urbanization (33). Our findings are consistent with those of other studies in that as a result of office jobs in the city and the use of technology, physical activity is reduced and the city population has a sedentary rather than an active lifestyle. Therefore, it is suggested that in areas with high levels of urbanization, the focus should be on environmental characteristics and providing facilities such as trails, parks, swimming pools, and gyms. Walking teams, teams for 


\begin{tabular}{|c|c|c|c|c|c|c|c|}
\hline \multirow[t]{2}{*}{ Risk factor } & \multirow[t]{2}{*}{ Urbanization level } & \multicolumn{3}{|c|}{ Crude OR } & \multicolumn{3}{|c|}{ Age-adjusted OR } \\
\hline & & OR & $95 \% \mathrm{Cl}$ & $P$-value & OR & $95 \% \mathrm{Cl}$ & $P$-value \\
\hline & \multicolumn{7}{|c|}{ Males } \\
\hline \multirow[t]{3}{*}{ Daily tobacco use } & Low & 1.00 & - & - & 1.00 & - & - \\
\hline & Medium & 1.02 & $0.84-1.24$ & 0.805 & 1.01 & $0.83-1.22$ & 0.885 \\
\hline & High & 0.90 & $0.74-1.10$ & 0.330 & 0.90 & 0.74-1.09 & 0.299 \\
\hline \multirow{3}{*}{$\begin{array}{l}\text { Low physical } \\
\text { activitya }\end{array}$} & Low & 1.00 & - & - & 1.00 & - & - \\
\hline & Medium & 1.60 & $1.33-1.94$ & $<0.001$ & 1.58 & $1.30-1.91$ & $<0.001$ \\
\hline & High & 1.72 & $1.42-2.08$ & $<0.001$ & 1.72 & $1.42-2.09$ & $<0.001$ \\
\hline \multirow{3}{*}{$\begin{array}{l}\text { Low fruit \& vegetable } \\
\text { intakeb }\end{array}$} & Low & 1.00 & - & - & 1.00 & - & - \\
\hline & Medium & 2.10 & $1.26-3.48$ & 0.004 & 2.08 & $1.25-3.46$ & 0.005 \\
\hline & High & 1.81 & $1.10-2.98$ & 0.019 & 1.80 & $1.09-2.96$ & 0.021 \\
\hline \multirow[t]{3}{*}{ High BMIc } & Low & 1.00 & - & - & 1.00 & - & - \\
\hline & Medium & 1.18 & 0.99-1.40 & 0.056 & 1.15 & $0.97-1.37$ & 0.107 \\
\hline & High & 1.44 & $1.21-1.71$ & $<0.001$ & 1.43 & $1.20-1.70$ & $<0.001$ \\
\hline \multirow{4}{*}{$\begin{array}{l}\text { High blood } \\
\text { pressured }\end{array}$} & Low & 1.00 & - & - & 1.00 & - & - \\
\hline & Medium & 1.25 & $1.00-1.57$ & 0.046 & 1.22 & $0.96-1.55$ & 0.099 \\
\hline & High & 0.90 & $0.71-1.14$ & 0.386 & 0.85 & 0.66-1.09 & 0.214 \\
\hline & \multicolumn{7}{|c|}{ Females } \\
\hline \multirow[t]{3}{*}{ Daily tobacco use } & Low & 1.00 & - & - & 1.00 & - & - \\
\hline & Medium & 0.70 & $0.50-0.99$ & 0.046 & 0.70 & $0.50-1.00$ & 0.050 \\
\hline & High & 0.85 & $0.61-1.19$ & 0.370 & 0.85 & $0.61-1.19$ & 0.360 \\
\hline \multirow{3}{*}{$\begin{array}{l}\text { Low physical } \\
\text { activitya }\end{array}$} & Low & 1.00 & - & - & 1.00 & - & - \\
\hline & Medium & 1.36 & $1.15-1.60$ & $<0.001$ & 1.36 & $1.15-1.60$ & $<0.001$ \\
\hline & High & 1.26 & $1.08-1.49$ & 0.004 & 1.26 & $1.08-1.49$ & 0.004 \\
\hline \multirow{3}{*}{$\begin{array}{l}\text { Low fruit \& vegetable } \\
\text { intakeb }\end{array}$} & Low & 1.00 & - & - & 1.00 & - & - \\
\hline & Medium & 1.44 & $0.92-2.27$ & 0.110 & 1.44 & $0.92-2.28$ & 0.109 \\
\hline & High & 1.22 & $0.78-1.91$ & 0.362 & 1.22 & $0.78-1.90$ & 0.367 \\
\hline \multirow[t]{3}{*}{ High BMIc } & Low & 1.00 & - & - & 1.00 & - & - \\
\hline & Medium & 1.21 & 1.05-1.39 & 0.006 & 1.25 & $1.08-1.44$ & 0.003 \\
\hline & High & 1.30 & $1.13-1.50$ & $<0.001$ & 1.32 & $1.14-1.53$ & $<0.001$ \\
\hline \multirow{3}{*}{$\begin{array}{l}\text { High blood } \\
\text { pressured }\end{array}$} & Low & 1.00 & - & - & 1.00 & - & - \\
\hline & Medium & 1.29 & $1.08-1.54$ & 0.005 & 1.44 & $1.18-1.76$ & $<0.001$ \\
\hline & High & 0.78 & $0.64-0.94$ & 0.011 & 0.72 & $0.59-0.89$ & 0.003 \\
\hline
\end{tabular}

$O R=$ odds ratio.

$\mathrm{Cl}=$ confidence interval.

$B M I=$ body mass inde .

$a_{<} 150$ min of moderate or intense physical activity per week.

$b_{<} 5$ servings of fruit and vegetables per day.

${ }^{c} B M I \geq 25 \mathrm{~kg} / \mathrm{m}$.

${ }^{d}$ Systolic blood pressure $\geq 140 \mathrm{mmHg}$ and/or diastolic blood pressure $\geq 90 \mathrm{mmHg}$.

beautifying green spaces, and increasing street lighting are effective in increasing physical activity $(32,33)$. In some studies, the likelihood of having high blood pressure was greater for residents of areas with high urbanization than for residents of other areas, after age adjustment $(26,29,30,34)$. Mathenge et al. found that likelihood of having hypertension was greater in urban residents than in rural residents after age and sex adjustment (27). A 2015 Chinese study concluded that environmental changes have a potential impact on systolic and diastolic blood pressure (35). Increased prevalence of high blood pressure can be attributed to increased environmental risk factors parallel to increased urbanization, while globally, high blood pressure is one of 


\begin{tabular}{|c|c|c|c|c|c|c|}
\hline \multirow[t]{2}{*}{ Outcome } & $\begin{array}{l}\text { Urbanization } \\
\text { level }\end{array}$ & $\begin{array}{l}\text { No. of people } \\
\text { in group }\end{array}$ & Mean & SD & $95 \% \mathrm{Cl}$ & $P$-value \\
\hline & \multicolumn{6}{|c|}{ Males } \\
\hline \multirow{3}{*}{$\begin{array}{l}\text { No. of servings of fruit and } \\
\text { vegetables per day }\end{array}$} & Low & 638 & 3.79 & 2.31 & $3.60-3.97$ & \multirow[t]{3}{*}{0.007} \\
\hline & Medium & 1488 & 3.84 & 1.84 & $3.75-3.94$ & \\
\hline & High & 1406 & 3.82 & 2.04 & $3.71-3.93$ & \\
\hline \multirow[t]{3}{*}{ BMI $\left(\mathrm{kg} / \mathrm{m}^{*} 2\right)$} & Low & 763 & 25.08 & 0.71 & $24.58-25.59$ & \multirow[t]{3}{*}{0.0001} \\
\hline & Medium & 1704 & 25.88 & 1.13 & $25.34-26.42$ & \\
\hline & High & 1632 & 26.28 & 1.28 & $25.65-26.90$ & \\
\hline \multirow[t]{3}{*}{ Systolic blood pressure $(\mathrm{mmHg})$} & Low & 763 & 124.57 & 19.12 & 123.21-125.92 & \multirow[t]{3}{*}{0.0001} \\
\hline & Medium & 1693 & 128.06 & 17.36 & 127.23-128.89 & \\
\hline & High & 1580 & 125.69 & 16.85 & $124.86-126.52$ & \\
\hline \multirow[t]{4}{*}{ Diastolic blood pressure $(\mathrm{mmHg})$} & Low & 763 & 78.63 & 12.49 & $77.74-79.51$ & \multirow[t]{3}{*}{0.0001} \\
\hline & Medium & 1693 & 77.67 & 11.48 & $77.12-78.22$ & \\
\hline & High & 1580 & 79.37 & 11.67 & $78.79-79.94$ & \\
\hline & \multicolumn{6}{|c|}{ Females } \\
\hline \multirow{3}{*}{$\begin{array}{l}\text { No. of servings of fruit and } \\
\text { vegetables per day }\end{array}$} & Low & 1045 & 3.66 & 2.07 & $3.53-3.79$ & \multirow[t]{3}{*}{0.0001} \\
\hline & Medium & 2088 & 3.83 & 1.88 & $3.75-3.91$ & \\
\hline & High & 2011 & 3.95 & 2.39 & $3.84-4.05$ & \\
\hline \multirow[t]{3}{*}{ BMI $\left(\mathrm{kg} / \mathrm{m}^{*} 2\right)$} & Low & 1235 & 26.83 & 1.67 & $25.89-27.76$ & \multirow[t]{3}{*}{0.0001} \\
\hline & Medium & 2347 & 27.79 & 1.30 & $27.26-28.32$ & \\
\hline & High & 2330 & 28.15 & 2.06 & $27.32-28.99$ & \\
\hline \multirow[t]{3}{*}{ Systolic blood pressure $(\mathrm{mmHg})$} & Low & 1234 & 122.45 & 21.68 & 121.23-123.66 & \multirow[t]{3}{*}{0.0001} \\
\hline & Medium & 2334 & 126.93 & 20.82 & $126.08-127.77$ & \\
\hline & High & 2247 & 120.85 & 19.96 & 120.03-121.66 & \\
\hline \multirow[t]{3}{*}{ Diastolic blood pressure $(\mathrm{mmHg})$} & Low & 1232 & 80.12 & 13.14 & $79.39-80.86$ & \multirow[t]{3}{*}{0.004} \\
\hline & Medium & 2334 & 78.74 & 12.15 & $78.24-79.23$ & \\
\hline & High & 2247 & 78.66 & 12.31 & 78.15-79.17 & \\
\hline
\end{tabular}

Means were compared using the Kruskal-Wallis test when assumptions for analysis of variance were not met. $S D=$ standard deviation .

$\mathrm{Cl}=$ confidence interval.

$B M I=$ body mass index .

*P-value for Kruskal-Wallis test.

the risk factors associated with number of deaths (36).

Our study has a cross-sectional nature, and thus no causality association can be deduced from it. In terms of the scale of urbanization, 2 provinces can have the same urbanization level, but may differ in other environmental dimensions that are likely to differentially affect health. Thus, more environmental research is needed to understand the implications of urbanizing the environment to develop an exposure measure for NCDs. Moreover, possible differences in factors probably caused by urbanization, such as stress levels and environmental factors, were not investigated; these could be considered valid for future population studies. Further development is required to understand the relative contribution of internet penetration, human development index, and each scale element for risk of chronic diseases. As self-reported information was received from participants regarding nutrition (fruit and vegetable consumption) and behavioural factors (smoking and physical activity), there is the possibility that information bias may have affected the results.

Our findingsindicate that increasing urbanization is related to the increased prevalence of several modifiable NCD risk factors that couldn serve as a basis for future studies, planning in order to manage health problems, determining the distribution of financial resources and human resources, and coordinating prevention and intervention strategies 
for NCDs based on different levels of urbanization.

\section{Conclusion}

In this study, urbanization was described and classified using different factors instead of the known rural/urban dichotomy, and a clear association was observed between different levels of urbanization and NCD risk factors. Increasing urbanization and its consequent complications requires policies and preparations by local governments to meet the needs of the community, which requires an intersectoral agreement and cooperation with other academic and administrative sectors.

Funding: This study was part of the MSc thesis of Zahra Khorrami, supported by Shahid Beheshti University of Medical Sciences (grant No.: /A/9294/36).

Competing interests: None declared.

\section{References}

1. Godfrey R, Julien M. Clin Med (Lond). 2005;5(2):137-41. PMID:15847005

2. Global status report on noncommunicable disease. Geneva: World Health Organization; 2010.

3. Al-Moosa S, Allin S, Jemiai N, Al-Lawati J, Mossialos E. Diabetes and urbanization in the Omani population: an analysis of national survey data. Popul Health Metr. 2006;4(1):5. PMID:16635266

4. UN high-level meeting on NCDS (New York, 19-20 September 2011): summary report of the discussions at the round tables. Geneva: World Health Organization; 2011 (http://www.who. int/nmh/events/moscow_ncds_2011/round_tables_summary.pdf, accessed 7 May 2017).

5. Cheema A, Adeloye D, Sidhu S, Sridhar D, Chan KY. Urbanization and prevalence of type 2 diabetes in Southern Asia: a systematic analysis. J Glob Health. 2014;4(1). PMID:2497696

6. Angkurawaranon C, Jiraporncharoen W, Chenthanakij B, Doyle P, Nitsch D. Urbanization and noncommunicable disease in Southeast Asia: a review of current evidence. Public Health. 2014;128(10):886-95. PMID:25369353

7. Lopez AD, Mathers CD, Ezzati M, Jamison DT, Murray CJ. Global and regional burden of disease and risk factors, 2001: systematic analysis of population health data. Lancet. 2006;367(9524):1747-57. PMID:16731270

8. Ezzati M, Lopez AD, Rodgers A, Vander Hoorn S, Murray CJ. Selected major risk factors and global and regional burden of disease. Lancet. 2002;360(9343):1347-60. PMID:12423980

9. Banwell C, Lim L, Seubsman S-A, Bain C, Dixon J, Sleigh A. Body mass index and health-related behaviours in a national cohort of 87,134 Thai open university students. J Epidemiol Community Health. 2009;63(5):366-72. PMID:19151014

10. Son P, Quang N, Viet N, Khai P, Wall S, Weinehall L, et al Prevalence, awareness, treatment and control of hypertension in Vietnam-results from a national survey. J Hum Hypertens. 2012;26(4):268-80. PMID:21368775

11. McDade TW, Adair LS. Defining the "urban" in urbanization and health: a factor analysis approach. Soc Sci Med. 2001;53(1):55-70. PMID:11380161

12. Mohan V, Mathur P, Deepa R, Deepa M, Shukla D, Menon GR, et al. Urban rural differences in prevalence of self-reported diabetes in India-The WHO-ICMR Indian NCD risk factor surveillance. Diabetes Res Clin Pract. 2008;80(1):159-68. PMID:18237817

13. Dahly DL, Adair LS. Quantifying the urban environment: a scale measure of urbanicity outperforms the urban-rural dichotomy. Soc Sci Med. 2007;64(7):1407-19. PMID:17196724.

14. Noshad S, Abbasi M, Etemad K, Meysamie A, Afarideh M, Khajeh E, et al. Prevalence of metabolic syndrome in Iran: A 2011 update. J Diabetes. May 2017;9(5):518-25.PMID: 27262869
15. Allender S, Foster C, Hutchinson L, Arambepola C. Quantification of urbanization in relation to chronic diseases in developing countries: a systematic review. J Urban Health. 2008;85(6):938-51. PMID:18931915

16. Allender S, Lacey B, Webster P, Rayner M, Deepa M, Scarborough $\mathrm{P}$, et al. Level of urbanization and noncommunicable disease risk factors in Tamil Nadu, India. Bull World Health Organ. 2010;88(4):297-304. PMID:20431794

17. Groth D, Hartmann S, Klie S, Selbig J. Principal components analysis. Methods Mol Biol. 2013;930:527-47.PMID: 23086856

18. Global physical activity surveillance. Geneva: World Health Organization; 2017 (http://www.who.int/chp/steps/GPAQ/ en/, accessed 8 May 2017).

19. STEPwise approach to surveillance (STEPS). Geneva: World Health Organization; 2017 (http://www.who.int/chp/steps/ en/, accessed 8 May 2017).

20. Effects of urbanization on incidence of noncommunicable diseases. Cairo: World Health Organization; 2012 (CommunityBased Initiatives Series 16).

21. Dong Y, Gao W, Nan H, Yu H, Li F, Duan W, et al. Prevalence of type 2 diabetes in urban and rural Chinese populations in Qingdao, China. Diabet Med. 2005;22(10):1427-33. PMID:16176207

22. Liu S, Wang W, Yang X, Lee ET, Zhang J, He Y, et al. Prevalence of diabetes and impaired fasting glucose in Chinese adults, China National Nutrition and Health Survey, 2002. Prev Chronic Dis. 2011;8(1)A13. PMID:21159225

23. Yarahmadi S, Etemad K, Hazaveh AM, Azhang N. Urbanization and noncommunicable risk factors in the capital city of 6 big provinces of iran. Iran J Public Health. 2013;42(Suppl. 1):113-8. PMID:23865027

24. Siddiqui ST, Kandala NB, Stranges S. Urbanisation and geographic variation of overweight and obesity in India: a cross-sectional analysis of the Indian Demographic Health Survey 2005-2006. Int J Public Health. 2015;60(6):717-26. PMID:26198774

25. Bjerregaard $P$, Jeppesen C. Inuit dietary patterns in modern Greenland. Int J Circumpolar Health. 2010;69(1):13-24.

26. Ezzati M, Hoorn SV, Lawes CM, Leach R, James WPT, Lopez $\mathrm{AD}$, et al. Rethinking the "diseases of affluence" paradigm: global patterns of nutritional risks in relation to economic development. PLoS Med. 2005;2(5):404. PMID:15916467

27. Mathenge W, Foster A, Kuper H. Urbanization, ethnicity and cardiovascular risk in a population in transition in Nakuru, Kenya: a population-based survey. BMC Public Health. 2010;10(1):569. PMID:20860807

28. Christensen DL, Eis J, Hansen AW, Larsson MW, Mwaniki DL, Kilonzo B, et al. Obesity and regional fat distribution in Kenyan populations: impact of ethnicity and urbanization. Ann Hum Biol. 2008;35(2):232-49. PMID:18428015 
29. Addo J, Smeeth L, Leon D. Hypertension in sub-Saharan Africa: a systematic review. Hypertension. 2007;50(6):1012-8. PMID:17954720

30. Reis JP, Bowles HR, Ainsworth BE, Dubose KD, Smith S, Laditka JN. Nonoccupational physical activity by degree of urbanization and US geographic region. Med Sci Sports Exerc. 2004;36(12):2093-8. PMID:15570145

31. Parks S, Housemann R, Brownson RC. Differential correlates of physical activity in urban and rural adults of various socioeconomic backgrounds in the United States. J Epidemiol Community Health. 2003;57(1):29-35. PMID:12490645

32. Allender S, Wickramasinghe K, Goldacre M, Matthews D, Katulanda P. Quantifying urbanization as a risk factor for noncommunicable disease. J Urban Health. 2011;88(5):906-18. PMID:21638117

33. Monda KL, Gordon-Larsen P, Stevens J, Popkin BM. China's transition: the effect of rapid urbanization on adult occu- pational physical activity. Soc Sci Med. 2007;64(4):858-70. PMID:17125897

34. Kamadjeu RM, Edwards R, Atanga JS, Kiawi EC, Unwin N, Mbanya JC. Anthropometry measures and prevalence of obesity in the urban adult population of Cameroon: an update from the Cameroon Burden of Diabetes Baseline Survey. BMC Public Health. 2006;6:228. PMID:16970806

35. Attard SM, Herring AH, Zhang B, Du S, Popkin BM, GordonLarsen $\mathrm{P}$. Associations between age, cohort, and urbanization with SBP and DBP in China: a population-based study across 18 years. J Hypertens. 2015;33(5):948-56. PMID:25668349

36. Choh AC, Nahhas RW, Lee M, Choi YS, Chumlea WC, Duren $\mathrm{DL}$, et al. Secular trends in blood pressure during early-tomiddle adulthood: the Fels Longitudinal Study. J Hypertens. 2011;29(5):838-45. PMID:21430562 